\title{
Open fetal surgery for myelomeningocele — is there the learning curve at reduction mother and fetal morbidity?
}

\author{
Ewa I. Horzelska ${ }^{1}$, Mateusz Zamlynski ${ }^{1}$, Tomasz Horzelski ${ }^{1}$, \\ Jacek Zamlynski ${ }^{1}$, Agnieszka Pastuszka ${ }^{2}$, Rafal Bablok ${ }^{1}$, \\ Izabela Herman-Sucharska ${ }^{3}$, Tomasz Koszutski ${ }^{2}$, Anita Olejek ${ }^{1}$ \\ ${ }^{1}$ Medical University of Silesia, Gynecology Clinical Care Unit, Obstetrics and Oncological Gynecology, Bytom, Poland \\ ${ }^{2}$ Medical University of Silesia, School of Medicine in Katowice, Department of Pediatric Surgery and Urology, Katowice, Poland \\ ${ }^{3}$ Collegium Medicum, Jagiellonian University, Department of Electroradiology, Cracow, Poland
}

\begin{abstract}
Objectives: We aimed to show how increased experience of a surgery team in $\mathrm{MMC}$ repair influences maternal and fetal/neonatal outcomes.

Material and methods: We compare perinatal results of fMMC repair in our Fetal Surgery Center (FSC) in cohort groups for the early period (2005-2011 year; previous - PFSC, $n=46$ ) and current period (2012-2015 year; current - CFSC, $n=74$ ) to results of the randomized Management of Myelomeningocele Study (MOMS, 78 patients).

Results: The maternal morbidity due to $\mathrm{AMMC}$ repair was low and there was no difference comparing CFSC to PFSC and MOMS. The frequency of iatrogenic preterm labor (iPTL) $\leq 30$ weeks of gestation decreased from $34.1 \%$ in PFSC to $23.9 \%$ in CFSC. latrogenic preterm premature rupture of membranes (iPPROM) was a common complication after $\mathrm{fMMC}$ repair in all cohorts. The total reduction rate of hindbrain hernation $(\mathrm{HH})$ was similar in CFSC $-90.3 \%$ and PFSC $-82.1 \%$.

Conclusions: The increasing experience of our surgery team in $\mathrm{AMMC}$ repair majorly decreased the risk of iPTL. Key words: myelomeningocele; fetal surgery; spina bifida; Chiari malformation
\end{abstract}

Ginekologia Polska 2020; 91, 3: 123-131

\section{INTRODUCTION}

Myelomeningocele (MMC) is a serious congenital defect of the central nervous system (CNS). It occurs if neurulation is not completed, which physiologically should happen between the $15^{\text {th }}$ and $30^{\text {th }}$ day after conception. MMC prevalence depends on race, sex, and geographical region. It affects about 3-4 per 10000 live births. In Poland the numbers reach 4-6 cases per 10000 live births [1].

The risk factors for MMC occurrence are: folic acid deficiency (seasonal or permanent), presence of $677 \mathrm{C}>\mathrm{T}$ polymorphism in the methylenetetrahydrofolate reductase gene, hyperthermia, low economic status, antispasmodic (especially valproic acid and carbamazepinum), antihistamine, and sulfonamides drug intake, increased BMI [2].

The pathogenesis of clinical signs of MMC is unclear. Two theories attempt to explain how abnormal cerebrospinal fluid (CSF) circulation influences this distinct anomaly of CNS. In the 'unified theory' of McLone and Knepper the CSF leakage results in posterior fossa compression and finally in development of hydrocephaly (HC) [3]. Regarding Heffez et al. neural defects in children with MMC are associated with a 'two hit theory' [4]. The disturbance of neurulation in the embryo is the first hit. The second one involves the inflammatory effect of amniotic fluid compounds and mechanical destruction of the protruding spinal cord that hits the uterine wall [4].

Clinical presentation of MMC in approximately $90 \%$ of the cases overlaps with the Arnold-Chiari syndrome [5]. The main consequences in later life include lower extremity paresis, urinary and bowel incontinence, sexual dysfunction and impaired psychomotor development [6, 7]. Sense and motor deficiency depend on the MMC location level $[6,7]$. 
Published data concerning prenatal evolution of Chiari Malformation type II (CM II) show that as the pregnancy progresses, hindbrain hernation $(\mathrm{HH})$ degree increases and the fourth ventricle and the venous sinuses are gradually being compressed $[6,7]$. This leads to inappropriate CSF circulation and progression of $\mathrm{HC}$ [2]. In more than $80 \%$ of children with CM II, the presence of $\mathrm{HC}$ in the postnatal period may entail the necessity of ventriculo-peritoneal shunt (VPS) implantation or endoscopic third ventriculostomy (ETV) [8]. In almost 50\% of patients, the drainage system must be replaced in their first year of life due to its frequent obstruction and infection [9].

In further development of children with CM II, in the event brain stem dysfunction is present; the mortality reaches 35\% during their first year of life [5].

The idea of in utero MMC repair that arises from the two 'hit theory' proposed by Heffez is confirmed in early pathomorphological studies as well as in experimental animal research [10]. The $\mathrm{AMMC}$ repair aims to protect the nerve fibres from the neurotoxic reaction caused by amniotic fluid compounds and to restore normal CSF circulation [11]. The $F M M C$ repair procedure counteracts the serious consequences of natural in utero evolution of CM II. The results of a randomized trial of prenatal versus postnatal repair of myelomeningocele publised in 2011 clearly showed that prenatal surgery for myelomeningocele reduced the need for shunting and improved motor outcomes at 30 months [5].

\section{Objectives}

We aimed to show how the increasing experience of our surgery team in $\mathrm{FMMC}$ repair majorly decreased the risk of iatrogenic preterm labor.

\section{MATERIAL AND METHODS}

Perinatal results of $\mathrm{FMMC}$ repair in the following cohort groups were compared:

- Previous study in our Fetal Surgery Center (FSC), from January 2005 to December 2011 (PFSC, $n=46$ ), [12] vs

- Current study in our FSC, from January 2012 to December 2015 (CFSC, $\mathrm{n}=74$ ), vs

- Management of Myelomeningocele Study (MOMS), from February 2003 through December $2010(n=78)$, [5].

\section{Patients qualification in Polish FSC, Bytom}

The procedure of $\mathrm{AMMC}$ repair has been performed in the FSC of the Clinical Department of Obstetrics, Gynecology, and Oncological Gynecology in Bytom, Poland since 2005 [13]. Seventy-four (74) of 183 patients with CM II referred to our FSC were qualified for $\mathrm{AMMC}$ repair, based on the protocol of the randomized MOMS criteria [5].
Major inclusion criteria were: maternal age $\geq 18$ years, single pregnancy, gestational age between 19 weeks, 0 days and 25 weeks, 6 days, location of fMMC at the S1 level or above with presence of Chiari II malformation in prenatal US and MRI, lateral ventricular size of $\mathrm{fMMC}$ less than $17 \mathrm{~mm}$, maintain lower extremities motor function, no other major anomalies, normal karyotype, normal feto-placental function and consent of the parents [5].

Major exclusion criteria were kyphosis $>30^{\circ}$, oligohydramnion, placenta previa, high risk of preterm labor (short cervix $\leq 20 \mathrm{~mm}$, previous preterm labours), previous hysterotomies, contraindication for epidural analgesia, maternal diseases like diabetes mellitus type 1, hypertension, obesity (BMI > 35), thrombophilia, and infectious diseases $(\mathrm{TORCH}$, abnormal bacterial flora in the cervical canal, respiratory tract infection, urinary tract infection, chronical infectious diseases of urinary tract) [13-15].

Like in other medical centers for maternal and fetal surgery, the decision of $\mathrm{fMMC}$ repair taken by the prospective parents was autonomous. The information about the FMMC repair procedure, the influence of CM II on child's further development and quality of life was presented by the perinatal team.

The primary end points were maternal morbidity, preterm labor ( $\mathrm{PPTL}) \leq 30$ weeks of gestation, iatrogenic preterm premature rupture of membranes (iPPROM), reduction of hindbrain herniation, severe infections $<7$ days of life. In order to objectively evaluate the posterior fossa, abnormality, based on MRI, grading was assigned as follows: grade 0, normal; grade 1, visible fourth ventricle and cisterna magna without cerebellar displacement below the foramen magnum, tentorium could be vertically oriented, and tectal breaking could be present; grade 2, visible cisterna magna without displacement of the cerebellum below the tentorium, no visible fourth ventricle; and grade 3, displacement of cerebellum below the foramen magnum and obliteration of all posterior fossa CSF spaces.

Grading was assigned by the attending neuroradiologist (L.T.B.). It was not possible to do this in a blinded manner, since the approximate age of the fetus and the preoperative or postoperative status was apparent from the MRI studies.

The evaluation of postoperative evolution of cerebral changes of $\mathrm{HH}$ and ventriculomegaly (VM) was based on $\mathrm{MRI}$, performed in $30^{+4}-33^{+0}$ gestational weeks in the group PFSC - 28/44 and CFSC - 31/71 (Fig. 1).

In addition, serial US examinations every 7-10 days after $\mathrm{fMMC}$ repair were performed to verify $C M$ II evolution, with measurement of the anterior diameter (AD) of $\mathrm{VM}, \mathrm{HH}$ degree, and fetal well-being.

Diagnosed $\mathrm{HH}$ degree was defined based on the Sutton et al. [16] scale. 

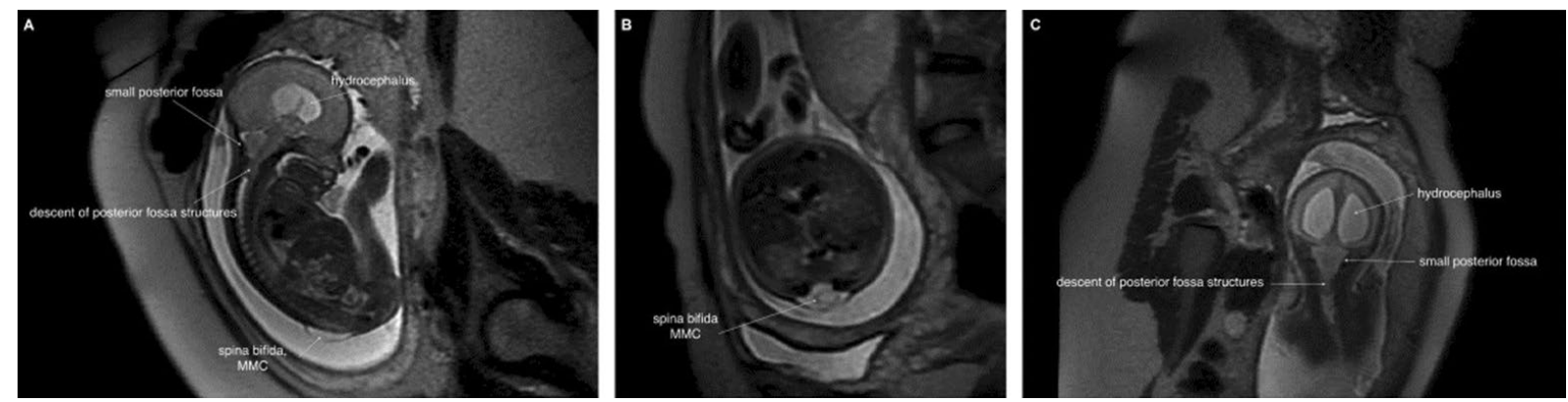

Figure 1. A. Fetal MRI, SSFSET2 sequence, sagittal plane: Chiari II - descent of the posterior fossa structures into cervical vertebral canal, small posterior fossa, supratentorial hydrocephalus, spin bifida cum myelomeningocele (arrows); B. Fetal MRI, SSFSET2 sequence, axial plane: Chiari II - spina bifida, myelomeningocele (arrows); C. Fetal MRI, SSFSET2 sequence, coronal plane: Chiari II — descent of the posterior fossa structures into cervical vertebral canal, small posterior fossa, supratentorial hydrocephalus (arrows)

VM was diagnosed when the atria of the lateral cerebral ventricles measure $>10 \mathrm{~mm}$ in diameter on an axial view of the fetal head, obtained at the level of the thalami [17]. The severity of VM was classified as: mild (lateral ventricular diameter between 10-12 mm), moderate (lateral ventricular diameter between 12.1-15 $\mathrm{mm}$ ), and severe (fetal VM > $15 \mathrm{~mm}$ ), sometimes also classified as fetal hydrocephaly (lateral ventricular diameter $>95$ pc) [18].

\section{Statistical analysis}

The analysis was performed using MedCalc 14.12.0 (MedCalc Software bvba, Ostend, Belgium). Values were presented as percentages and mean values \pm SD and ranges. The comparison of qualitative variables with data in published cohorts was done with $x^{2}$ or $x^{2}$ for trend tests. The difference was considered statistically significant when, the ' $p$ ' value was below 0.05 .

\section{fMMC repair — surgical protocol}

Twenty-four hours before the $\mathrm{AMMC}$ repair procedure, Betamethasone $24 \mathrm{mg}$ (as RDS prevention) Ceftazidime $2.0 \mathrm{~g}$ i.v (antibiotic prophylaxis), Indomethacin $150 \mathrm{mg} / 24 \mathrm{~h}$, and Nifedipine $40 \mathrm{mg} / 24 \mathrm{~h}$ (tocolytic treatment) were administered.

The surgery was conducted under simultaneous general anesthesia and subdural analgesia. The abdomen was opened with the Pfannenstiel incision or in the scar after previous laparotomy. The incision of the uterine muscle was made in the mid sagittal line above the $M M C, \geq 5 \mathrm{~cm}$ from the placenta margin. The amniotic fluid was then extracted and the incision was enlarged using Auto Suture Poly $\mathrm{CS}^{\mathrm{TM}}$ stapler (Covidien Mansfield, MA, US). The fMMC was manually placed into the hysterotomy site. For fetal anesthesia, opioids (fentanyl $10-20 \mathrm{mcg} / \mathrm{kg}$ ) and muscle a relaxant drug (Pancuronium 0.1-0.3 mg/kg) were administered.

There are essentially no differences between prenatal and postnatal procedures performed by the pediatric sur- geons during MMC repair. Waterproof closing of the dura is usually very difficult due to the tissue fragility. In our opinion the most important part of MMC closing is placode and cauda equine release. The next step is mobilization of the fascio-muscular layers from the both sides (erector spinalis muscles) to the median line applying single sutures. Suturing of the skin caused minor difficulties but, when it is necessary, relaxing incisions, or slight cutaneous flap movements, were performed. The fetal part of the surgery on average takes 30-40 min but up to $60 \mathrm{~min}$ in very difficult cases.

The amniotic fluid was supplemented with warm crystalloid fluids. The closure of the uterine muscle with two layers of monofilament continuous suture was preceded by intra-amniotic infusion of $1.0 \mathrm{~g}$ Ceftazidime. Figure 2 presents the $\mathrm{AMMC}$ repair steps.
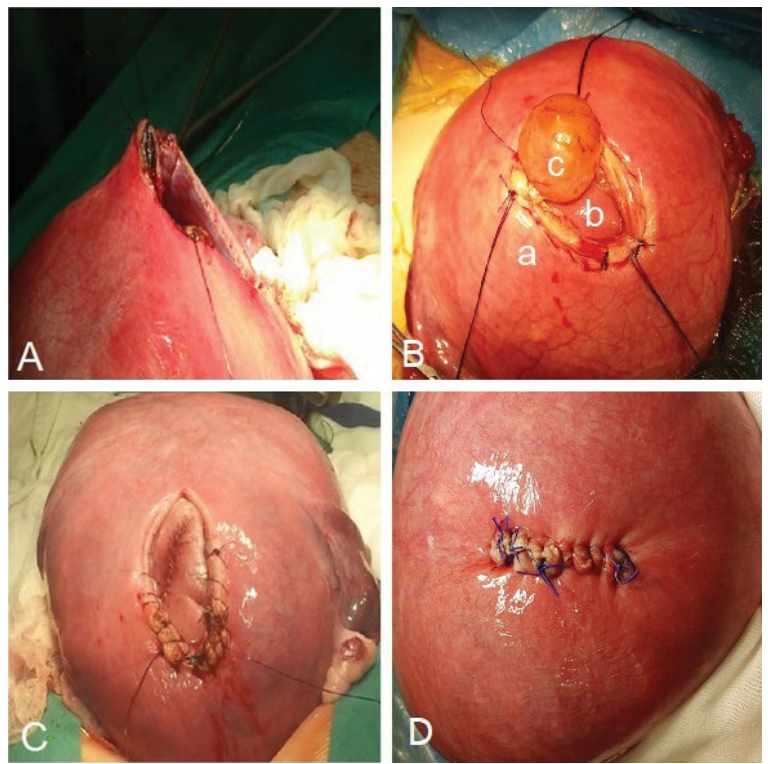

Figure 2. The stages of $\mathrm{AMMC}$ repair (A - hysterotomy, $B$ - stabilization of fetus with exposed MMC, $a$ - uterus, $b$ - fetus back, c - MMC sack, C — closed MMC, D - closed uterus); MMC - myelomeningocele 
Magnesium sulfate $2 \mathrm{~g}$ i.v was administered when opening and closing the uterine muscle. The hemodynamic condition of the fetus was monitored by Doppler ultrasound by analyzing FHR and PI indices of the umbilical artery.

After the operation, all women were monitored for signs of intrauterine infection such as: increased basal body temperature, maternal heart rate, fetal heart rate, C-reactive protein, and procalcitonin. Antibiotic prophylaxis was continued until postoperative day 7 with Ceftazidime $2.0 \mathrm{~g} / 24 \mathrm{~h}$ i.v. Analgesic treatment included Marcaine through an epidural catheter $<7$ days. Tocolytic treatment included Nifedipine $20 \mathrm{mg} / 24 \mathrm{~h}$ p.o. and Fenoterol Hydrobromide $20 \mathrm{mg} / 24 \mathrm{~h}$ p.o. The information concerning postoperative management was discussed in detail in our previous study and MOMS study [5, 12].

In the $\mathrm{fMMC}$ repair group an elective cesarean section was performed at 37 weeks of gestation, or earlier if the complications threatened maternal or fetal life. The condition of the uterine scar after hysterotomy was assessed during the cesarean section.

\section{RESULTS}

Data of the study population is presented in Table 1. Our study group consisted of 74 patients, but because of three fetal death [1 intraoperation fetal death (IUFD) and 2 within 24 hours after $\mathrm{FMMC}$ repair (NND)] in the final analysis we took into consideration 71 neonates, except for mortality rate.

Range of gestational age at the time of fetal surgery for MMC was defined as $19^{+0}-25^{+6}$, according to inclusion criteria. In our study fMMC repair performed between $22^{+3}$ $-25^{+6}$ weeks of gestation. Nearly half of the patients were op-

\begin{tabular}{|c|c|}
\hline $\begin{array}{l}\text { Gestational age at IUMR based on last } \\
\text { menstrual period and ultrasound in } 11- \\
14 \text { weeks of gestation; mean (range) }\end{array}$ & $23^{+6} \pm\left(22^{+3}-25^{+6}\right)$ \\
\hline Normal feto-placental function; $\mathrm{n}(\%)$ & $74(100)$ \\
\hline $\begin{array}{l}\text { Lower extremities motor function/feet } \\
\text { deformity; } \mathrm{n}(\%)\end{array}$ & $53(71.6)$ \\
\hline $\begin{array}{l}\text { Increased lateral ventricles width anterior } \\
\text { diameter; } \mathrm{n}(\%)\end{array}$ & $61(82.4)$ \\
\hline \multicolumn{2}{|l|}{ fMMC level; n (\%) } \\
\hline$\geq \mathrm{Th}_{12}$ & 0 \\
\hline $\mathrm{L}_{1}-\mathrm{S}_{1}$ & $66(89.2)$ \\
\hline$<\mathrm{S}_{1}$ & $5(6.8)$ \\
\hline \multicolumn{2}{|l|}{ Degree of hindbrain herniation; $\mathrm{n}(\%)$} \\
\hline 0 - absent & 0 \\
\hline I-low & $7(9.5)$ \\
\hline$\|$ - moderate & $64(86.5)$ \\
\hline III - severe & 0 \\
\hline
\end{tabular}

erated in $23^{+6}$ weeks of gestation. Five (6.8\%) patients with low $\mathrm{fMMC}$ location $<\mathrm{S}_{1}$ were exposed to early MRI between $19^{+2}-21^{+3}$ weeks of gestation and CM II was diagnosed only in a single case. Among the remaining 4 patients, MRI was repeated in 25 weeks and late $\mathrm{HH}$ and VM which qualified for $\mathrm{AMMC}$ repair were diagnosed.

The maternal morbidity after $\mathrm{FMC}$ repair encompasses typical complications for surgical operations during pregnancy. Pre-edematous state of pulmonary edema as well as peritonitis was observed only in 1 patient in both current and previous study (accordingly $1.4 \%$ vs $2.2 \%$ ). The need of blood transfusion occured in 4 (5.4\%) patients in CFSC group and in $3(6.5 \%)$ patients in PFSC group. Comparing CFSC to MOMS and PFSC, the frequency of complications which could cause serious consequences (pre-edematous state without secondary intubation and ICU treatment, blood loss and peritonitis) were low and comparable (Tab. 2).

The analysis of perinatal results after $\mathrm{AMMC}$ repair in CFSC group showed following complications: iatrogenic oligohydramnion 12/71 (16.9\%), chorioamniotic membrane separation (CMS) 11/71 (15.5\%) and was insignificant compared to MOMS and our previous study PFSC, respectively: 16 (21), 20 (26) vs 4 (8.7\%), 8 (17.3\%). iPPROM was the most frequent iatrogenic complication after $\mathrm{AMMC}$ repair and its frequency in CFSC was 31/71 (43.6\%) of similarly high frequency of iPPROM noted in MOMS 36/78 (46.2\%) and in our study from the previous period PFSC 24/46 (52.2\%). Despite the positive trend, the comparison of the results of all cohorts does not achieve statistical significance. $\mathrm{iPTL} \leq 30$ weeks of gestation which is a serious consequence of iPPROM occurred in 17/71 (23.9\%) patients in our centre where as in 10/78 (12.8\%) in Adzick's study. Comparing this value with PFSC $15 / 44$ (34.1\%) is not significant. Site evaluation during cesarean section points to a completely healed, hysterotomy site, in the CFSC cohort 63/71 (88.7\%) vs MOMS 49/76 (64.5\%), $\mathrm{p}<0.001$. In two patients in CFSC and PFSC (accordingly 4,1\% and 6,5\%) during cesarean section we observed complete dehiscence of hysterotomy site which needed surgical repair. It was the only complication which we reported during cesarean section in our patients.

Our data indicates that $17 / 71$ (23.9\%) of children were born in $\geq 37$ weeks of gestation and it was similar in MOMS study. The result of labour $\geq 37$ weeks improved compared to our last observation (PFSC) where this value was lower $8 / 44$ (18.2\%) vs MOMS 16/78 (20.5\%), $\mathrm{p}<0.05$.

\section{Fetal results}

$\mathrm{HH}$ improvement despite greater number of phenomenon, did not achieve statistical significance in comparing CFSC vs PFSC, respectively for degree: partial $\geq 1^{\circ}$ $15 / 31(48.4 \%)$ vs $13 / 28$ (46.4\%), complete $13 / 31$ (41.9\%) vs $10 / 28(35.7 \%)$ and any $28 / 31$ (90.3\%) vs $23 / 28(82.1 \%)$. 


\begin{tabular}{|c|c|c|c|}
\hline & $\begin{array}{l}\text { CFSC } \\
n=74\end{array}$ & $\begin{array}{l}\text { MOMS } \\
\text { Adzick 2011[5] } \\
\mathrm{n}=78\end{array}$ & $\begin{array}{l}\text { PFSC } \\
\text { Zamłyński } 2014 \text { [12] } \\
n=46\end{array}$ \\
\hline \multicolumn{4}{|l|}{ Maternal results $\mathrm{n}(\%)$} \\
\hline $\begin{array}{l}\text { Pre-edematous state of pulmonary edema without secondary intubation and } \\
\text { intensive care unit treatment }\end{array}$ & $1(1.4)$ & $5(6.4)$ & $1(2.2)$ \\
\hline Preeclampsia/Hypertension & $3(4.1)$ & $3(3.8)$ & $2(4.3)$ \\
\hline Gestational diabetes mellitus & $2(2.7)$ & $4(5.1)$ & $1(2.2)$ \\
\hline Blood transfusion & $4(5.4)$ & $7(9.0)$ & $3(6.5)$ \\
\hline Peritonitis & $1(1.4)$ & $2(2.6)$ & $1(2.2)$ \\
\hline \multicolumn{4}{|l|}{ Amniotic membranes and amniotic fluid $\mathrm{n}(\%)$} \\
\hline Chorioamniotic membrane separation (CMS) & $11 / 71(15.5)$ & $20(25.6)$ & $8(17.3)$ \\
\hline iatrogenic oligohydramnios $\mathrm{AFI}<5 \mathrm{~cm},>21$ days & $12 / 71(16.9)$ & $16(20.5)$ & $4(8.7)$ \\
\hline iPPROM syndrome & $31 / 71(43.6)$ & $36(46.2)$ & $24(52.2)$ \\
\hline Chorioamnionitis & $3 / 71(4.2)$ & $2(2.6)$ & $2(4.3)$ \\
\hline Preterm placental abruption & $2 / 71(2.8)$ & $5(6.4)$ & $2(4.3)$ \\
\hline \multicolumn{4}{|l|}{ Hysterotomy site (evaluation during cesarean section) n (\%) } \\
\hline Completely healed & $63 / 71(88.7)^{\# \# \#}$ & $49 / 76(64.5)$ & $34(73.9)$ \\
\hline Partial dehiscence & $4 / 71(5.6)$ & $7 / 76(9.2)$ & $3(6.5)$ \\
\hline Complete dehiscence & $2 / 71(2.8)$ & $1 / 76(1.3)$ & $2(4.3)$ \\
\hline $\begin{array}{l}\text { Fetal extrusion into peritoneal cavity (complete uterine rupture with intact } \\
\text { membranes and placenta) }\end{array}$ & $1 / 71(1.4)$ & 0 & $1(2.2)$ \\
\hline
\end{tabular}

$\# \#$ p $<0.001$

Only in two fetuses with CM II, in both cohorts, was observed $\mathrm{HH}$ progression $\geq 1^{\circ}$ and in 6 cases $\mathrm{HH}$ degree after fMMC repair did not change.

We compared the width of the lateral ventricle before and after IUMR measuring AD in degree: mild (10-12 $\mathbf{~ m m}$ ) or moderate (12.1-15 $\mathrm{mm}$ ). It was observed significant inhibition of VM development in CFSC vs PFSC respectively: $25 / 31(80.6 \%)$ vs $15 / 28(53.6 \%), p<0.05$. The comparison of width of the lateral ventricle in MRI during qualification and after $\mathrm{FMMC}$ repair (in $30^{+4}-33^{+0}$ gestational week) point to VM inhibition in the groups CFSC vs PSC in the following way: $25 / 31(80.6 \%)$ vs $15 / 28$ (53.6\%), p < 0.05 . We did not achieved improvement relative to frequency of progressive VM/HC > 95\% comparing our cohorts. In 5 (17.8\%) fetuses with $\mathrm{MMC}$ localization $<\mathrm{S}_{1}$, VM was not still observed after fMMC repair.

\section{Neonatal results}

In infants born prematurely, advanced neonatal procedures as nCPAP ventilation support 24/71 (33.8\%) and mechanical ventilation 19/71 (26.7\%) were applied. Comparing CFSC vs MOMS, ventilation support for respiratory distress syndrome was required $43 / 71$ (60.6\%) vs $16 / 77$ (21\%) infants, $\mathrm{p}<0.001$. Concerning the neonatal outcome the cumulative mortality stands at 4/74 (5.4\%) in our centre.
Unexpected, intracranial haemorrhage $(\mathrm{IH}) \mathrm{I}^{0}-\mathrm{II}^{0}$ was observed in a statistically significant frequently in CFSC vs PFSC following: 34/71 (47.9\%) vs 4/44 (9.1\%), p < 0.001. However, $\mathrm{IVH} \mathrm{I}{ }^{0}$ without clinical syndromes were observed using ultrasound examination in near half of cases in the CFSC group $34 / 71$ (47.9\%). A high percentage was observed of neonatal infections diagnosed $<7$ day of life: CFSC 25/71 (35.2\%) and PFSC $12 / 24$ (50\%), which could be attributed to the need for invasive neonatal procedures. Despite the improvement of these results, the difference is statistically insignificant. The frequency of a serious complication, sepsis in our cohorts, CFSC 5/71 (7.0\%) and PFSC 2/24 (8.3\%) was low and is comparable with those reported in MOMS 4/77 (5.2\%).

The final effect of changes in the CNS structures in the form of decreasing $\mathrm{HH}$ was observed in our study in 28/31 (90.3\%) of fetuses with CM II whereas non-progressive VM diagnosed in ultrasonography examination before cesarean section concerned $25 / 31$ (80.6\%) of fetuses with fMMC.

\section{DISCUSSION}

Up until 1997, only postnatal treatment served as a therapeutic option that eased the consequences of in uterine damage of the nervous system in fetuses with CM II. The first fMMC repair in the US (CHOP and VUMC) has brought surgical procedures to Europe and beyond. The results of these 
studies were reported as short term observational studies of cohort groups. The comparison of qualification criteria and surgical protocols remain unanimous $[5,12,14,19]$. Whereas long-term observation of childhood development after $\mathrm{FMMC}$ repair was assessed only in the CHOP study $[20,21]$.

The maternal morbidity after $\mathrm{AMMC}$ repair is typical surgical complications such as blood loss and peritonitis (Tab. 2). Gollombeck et al. [22] in 2006, noted that the most common complications after maternal-fetal surgery was a higher incidence of lung edema and respiratory insufficiency $(27.6 \%)$, re-intubation (2.3\%), and intensive care treatment. The MOMS study and our own experiences, as well as the recent VUMC study, have shown that maternal safety increased significantly $[5,12,23]$, in contrast with previous data from Moldenhauer et al. [24] In post-MOMS analysis at the Children's Hospital of Philadelphia, showed lower complication rates than in the actual trial, including pulmonary oedema 2/100 (2\%). Furthermore, in our cohorts, the results of maternal morbidity show lower health risk during the intraoperative period. Al-Refai et al. [25], analyzing maternal morbidity associated with various perinatal invasive procedures, concluded that adverse maternal effects are probably rare, when done in an expert center.

Moreover, using atosiban instead of magnesium sulfate in the context of open fetal surgery may significantly improve the maternal safety [26].

Perinatal iatrogenic complications of the uterine-placental-fetal unit are the main limitation of $\mathrm{MMMC}$ rehabilitation and they result from the invasive surgical procedure and pharmacological treatment [15]. Pulmonary oedema is the main iatrogenic complications for mother and it results from the use of high doses of magnesium sulfate. Whereas the use of COX-1 and COX-2 inhibitors can lead to oligohydramnions which results from the inhibition of fetal urine production.

In the current studies, iatrogenic iPPROM, iatrogenic oligohydramnion, and CMS were reported in 31/71 (43.6\%), $12 / 71(16.9 \%)$ and $11 / 71$ (15.5\%) cases, respectively. Unfortunately, these values remain comparable. CFSC vs PFSC, and insignificant compared to the MOMS results [5]. In the Soni et al. [27] study, frequency of CMS was $21 / 88$ (23.9\%) and iPPROM occurred in 27/88 (30.7\%) of cases after fMMC repair. In this study, local or global CMS, which was diagnosed by ultrasound, was significantly associated with iPPROM (59.1 vs $21.2 \%, p=0.008$ ) and earlier gestational age at delivery $(32.1 \pm 4.2$ vs $34.4 \pm 3.5$ weeks, $p=0.01)$.

In our study, iatrogenic preterm labor, $\leq 30$ weeks of gestation, occurred in 17/71 (24) cases as a consequence of iPPROM. 17 (24\%) children were born in $\geq 37$ weeks of gestation. Many of the unfavorable perinatal outcomes were demonstrated as early experiences of our FSC. In more recent observations the perinatal outcomes have improved as the result of learning curve [15]. It is worth to emphasis that the learning curve has certainly the influence in the reduction of perinatal complication but after achieving some ability, the rate of complications remain on the stable level.

The main results concerning neonates are caused by complications after $\mathrm{FMMC}$ repair. In our current study, one fetal death and one miscarriage in $22^{+3}$ occurred during fMMC repair before uterine muscle closure. Three pregnancies lost in $24^{+2}, 25^{+2}$ and $24^{+4}$ weeks occurred up to 48 hours after IUMR due to severe CMS, iPPROM, and placental abruption. In comparison to other researchers, the cumulative postnatal mortality is of acceptable value and much like the MOMS study results and other reports $[5,12,15]$. The total frequency of prematurity $\leq 30$ weeks in comparison of our cohorts was the following: CFSC $17 / 71$ (23.9\%) vs PFSC 15/44 (34.1\%) and it is notably, but not significantly lower. Prematurity contributed to an increase necessity to apply ventilation support for RDS in the following: CFSC 43/71 (60.6\%) vs MOMS 16/77 (20.8\%) $p<0.001$ [5].

It is necessary to emphasize that not only prematurity caused by $\mathrm{AMMC}$ repair, but also CM II neurological dysfunctions are the independent risk factors for increased intensive neonatal care procedures, even among newborns born at term. Da Silva et al. reported that in 97 newborns delivered $\geq 37$ weeks of gestation with untreated CM II, the neurological dysfunction were the reason for nCPAP ventilation in 29/97 (29.9\%) (OR 4.55, 95\%, Cl 1.82-11.41) and newborn intubation in 13/97 (13.4\%) (OR 3.94\%, $\mathrm{Cl}$ 1.14-13.59) [28]. At one minute after birth 24 newborns were scored < 7 Apgar points (OR 95\%, Cl 0.99-7.57) [28].

The main aim of $\mathrm{FMMC}$ repair is the neuroprotection of exposed spinal cord nerve fibres from toxic effect of amniotic fluid and secondarily to restrict the evolution of CM II cerebral changes in the form of VM and $\mathrm{HH}$ [29].

The evaluation of the brain in magnetic resonance imaging in $30^{+4}-33^{+0}$ gestational week points to a high percentage of improvement in hindbrain herniation in our cohorts: CFSC 28/31 (90.3\%) and PFSC 23/28 (82.1\%). Additionally, we obtained significant improvement into fetal conditions in the form of non-progressive VM: CFSC $25 / 31$ (80.6\%) vs $15 / 28(53.6 \%), p<0.05$.

The evolution of changes in the CNS observed after fMMC repair can prove to restore a normal CSF circulation. Danzer et al. [30] demonstrated that as the pregnancy progressed the lateral ventricular width did not increase in 22 fetuses after $\mathrm{FMMC}$ repair, contrary to the fetuses with CM II treated postnatally. In our previous study we observed stationary VM with ventricular width not exceeding the diameter measured at the time of surgical qualification in $53 \%$ cases after $\mathrm{fMMC}$ repair and in $13 \%$ cases without treatment (Cl 4.01, 1.05-15.3, p=0.04) [12]. Decreased VM incidence in children that underwent $\mathrm{FMMC}$ repair is associated with the 
Table 3. A comparison of fetal condition and evolution of CM II and neonatal results after fMMC repair

\begin{tabular}{|l|l|l|l|}
\hline & CFSC $\mathbf{n = 7 4}$ & MOMS Adzick 2011[5] $\mathbf{n = 7 8}$ & PFSC Zamłyński 2014 [12] $\mathbf{n = 4 6}$ \\
\hline Mortality, $\mathbf{n}$ (\%) & & & \\
\hline Intrauterine foetal death (IUFD) & $1 / 74(1.4)$ & 0 & 0 \\
\hline $\begin{array}{l}\text { Neonatal death (NND) }<7 \text { days } \\
\text { Cumulative }\end{array}$ & $3 / 74(4.1)$ & $2(2.6)$ & $2(4.3)$ \\
\hline Gestational age at delivery, $\mathbf{n}$ (\%) & $4 / 74(5.4)$ & $2(2.6)$ & $2(4.3)$ \\
\hline$\leq 30$ weeks & $17 / 71(23.9)$ & $10(12.8)$ & $15 / 44(34.1)$ \\
\hline $31-33$ weeks & $16 / 71(22.5)$ & $26(33.3)$ & $11 / 44(25)$ \\
\hline $34-36$ weeks & $24 / 71(33.8)$ & $26(33.3)$ & $10 / 44(22.7)$ \\
\hline$\geq 37$ weeks & $17 / 71(23.9)$ & $16(20.5)$ & $8 / 44(18.2)$ \\
\hline
\end{tabular}

Evaluation of the brain in magnetic resonance imaging $\left(30^{+4}-33^{+0}\right.$ gestational week)

Hindbrain herniation improvement, $\mathrm{n}(\%)$

\begin{tabular}{|l|l|l|l|}
\hline Partial $\geq 1^{\circ}$ & $15 / 31(48.4)$ & n.a. & $13 / 28(46.4)$ \\
\hline Complete & $13 / 31(41.9)$ & & $10 / 28(35.7)$ \\
\hline Any ${ }^{X}$ & $28 / 31(90.3)$ & & $23 / 28(82.1)$ \\
\hline
\end{tabular}

Hindbrain herniation progression, $\mathbf{n}(\%)$

Moderate $\geq 1$

$1 / 31(3.2)$

0

Severe $\geq 2^{\circ}$

Lateral ventricles width, $\mathrm{n}(\%)$

Non-progressive $\mathrm{VM}^{*}$

$25 / 31(80.6) \wedge$

n.a.

$15 / 28(53.6)$

Progressive VM/HC $>95 \% * *$

$6 / 31(19.3)$

Neonatal weight, $\mathrm{n}(\%)$

$<3$ percentile

$<10$ percentile

$3 / 71(4.2)$

$12 / 71(17)^{\#}$

n.a.

$1 / 28(3.6)$

0

Fifth minute Apgar score, $\mathbf{n}(\%)$

$0-3$

4-7

$6 / 71(8.4)$

28/71 (39.4)

8-10

$37 / 71(52.1)$

Ventilation support for respiratory distress syndrome (RDS), $\mathbf{n}(\%)$

\begin{tabular}{|c|c|c|c|}
\hline nCPAP & $24 / 71(33.8)$ & n.a. & $11 / 44(25.0)$ \\
\hline Mechanical ventilation & $19 / 71(26.7)$ & & $12 / 44(27.3)$ \\
\hline Any support & $43 / 71(60.6)^{\# \#}$ & $16 / 77(20.8)$ & $23 / 44(52.7)$ \\
\hline \multicolumn{4}{|c|}{ Intracranial haemorrhage (IH), n (\%) } \\
\hline I-II grade & $34 / 71(47.9) \wedge \wedge \wedge$ & n.a. & $4 / 44(9.1)$ \\
\hline III-IV grade & $2 / 71(2.8)$ & & $1 / 44(2.3)$ \\
\hline Any IH & $36 / 71(50.7)^{\wedge \wedge \wedge}$ & & $5 / 44(11.4)$ \\
\hline \multicolumn{4}{|l|}{ Infections $<7$ days, $\mathrm{n}$ (\%) } \\
\hline Sepsis*** & $5 / 71(7.0)$ & $4 / 77(5.2)$ & $2 / 24(8.3)$ \\
\hline Other neonatal infection & $20 / 71(28.1)$ & n.a. & $10 / 24(41.7)$ \\
\hline Any infection & $25 / 71(35.2)$ & & $12 / 24(50.0)$ \\
\hline MMC wound dehiscence, n (\%) & $14 / 71(19.7)$ & $10 / 77(13.0)$ & n.a. \\
\hline Foot deformity, n (\%) & $32 / 71(45.1)$ & $39 / 77(50.6)$ & $11 / 44(45.8)$ \\
\hline
\end{tabular}

$\wedge \mathrm{p}<0.05 ; \wedge \wedge \wedge \mathrm{p}<0.001$ vs PFSC; $\mathrm{p}<0.05 ;{ }^{\# \# \#} \mathrm{p}<0.001$ vs MOMS; ${ }^{\mathrm{x}}-\mathrm{HH}$ improvement was defined as: partial- reduction of HH degree about $1^{\circ}\left(\right.$ from $2^{\circ}$ to $\left.1^{\circ} \mathrm{HH}\right)$; complete - redaction of $\mathrm{HH}$ degree from $2^{\circ}$ to $0^{\circ}$ or $1^{\circ}$ to $0^{\circ} ;{ }^{*}$ Non-progressive VM - was defined as the some VM class before and after fMMc repair ( $\mathbf{m i l d}$ fetal ventriculomegaly: lateral ventricular AD between 10-12 mm or moderate fetal VM: AD 12.1-15 mm); ${ }^{* *}$ Progressive VM/HC $>95 \%$ was defined as increased VM class to severe fetal ventriculomegaly also sometimes classified as fetal $\mathrm{HC}$ (head circumference $>95 \%$ in given gestational age) lateral ventricular AD $>\mathbf{1 5}$ mm; *** Sepsis was defined as confirmation on blood culture $\mathrm{G}(-), \mathrm{G}(+)$ at 7 days 
decreased necessity of VPS implantation or EVS [14]. Adzick et al. [6] showed a significantly decreased VPS implantation rates in children treated in utero in their first year of life (40\% vs $82 \%$ in postnatal group). In a observational study over 53 months published by Zamłyński et al. [12] the necessity ofVPS implantation in 18 cases from the fMMC repair group included 5 children (27.8\%). In a control group it amounted to $80 \%(\mathrm{Cl} 0.35,0.16-0.75, \mathrm{p}<0.008)$ [22]. In the study of 30 children, aged 5 , that underwent $\mathrm{AMMC}$ repair without VPS implantation, better cognitive function $(p=0.02)$, enhanced motor function of lower extremities $(p<0.02)$, and an increased number of children to fully care for themselves ( $p<0.01$ ) were observed (in comparison to the children with postnatal treatment followed by VPS implantation) [22]. In a further study of children who were 10 years old after $\mathrm{fMMC}$ repair, in $90 \%$ self-reliance and good life quality were affirmed [23].

The purpose of in utero $\mathrm{FMMC}$ repairs that have lasted for three decades was finally proved by the randomized MOMS trial which is considered a milestone in the field of perinatology. This study closes the period of uncertainty concerning $\mathrm{AMMC}$ repair validity. The $\mathrm{FMMC}$ repair gained a permanent place among perinatal procedures despite iatrogenic complications. In 2013 ACOG published an opinion concerning prenatal MMC repair in CM II, [31]. Additionally, SGOCC suggested in 2014 that due to possibility of prenatal surgery, parents of children with CM II should be fully informed about the procedure and post-operative course of the disease [32].

\section{Historical data and perspectives for $\mathrm{AMMC}$ repair in Europe}

The Experimental basis for human $\mathrm{FMMC}$ repair in animal models was created in Europe and in the US [10]. In the report of Meuli et al. [11] published in 1995, in Nature Medicine, the description of artificial MMC closure in sheep was introduced. It has been proved that intrauterine protection of spinal cord fibres against injury and toxicity of amniotic fluid prevents CNS destruction and worsening of vegetal function [11]. In Europe, the first $\mathrm{AMMC}$ repair performed in FSC in Bytom in the year 2005 was followed by the successful procedure in Zurich in 2010, and cases reported in 2014 by Oveare (in Europe, the first $\mathrm{FMMC}$ repair performed in FSC in Bytom in the year 2005 was followed by the successful procedure in Zurich in 2010, and cases reported in 2014 by Ovaere from Leuven $[33,34])$. In the few centers in the world also in Poland (The University of Warsaw) fetoscopic prenatal surgical repair of MMC is used. This minimally invasive technique is a promising alternative to open fetal MMC repair but still requires improvement.

European medical organizations are trying to work out the consensus and guidelines for patient with MMC [35].
It should presumed that an increasing level of medical acceptance of prenatal therapy and the ability to provide nondirective information for parents of CM II children contribute to an increasing frequency and number of IUMR-centres in Europe.

\section{CONCLUSIONS}

FMMC repair is an invasive procedure; however, the level of maternal-fetal surgery safety is quite high. Comparison of fetal condition and neonatal results after $\mathrm{AMMC}$ repair: CFSC vs MOMS vs PFSC, points to good effectiveness in reduction of hindbrain herniation $(\mathrm{HH})$ and reduction or prevention ventriculomegaly (VM). The learning curve is positive, mostly decreasing the risk of iatrogenic preterm labor.

\section{REFERENCES}

1. Congenital defects in Poland in years 2005-2006. Polish register of congenital defects. Poznan 2010. http://www.rejestrwad.pl/str.php?13.

2. Giardini V, Russo FM, Ornaghi S, et al. Seasonal impact in the frequency of isolated spina bifida. Prenat Diagn. 2013; 33(10): 1007-1009, doi: 10.1002/pd.4175, indexed in Pubmed: 23749491.

3. McLone DG, Knepper PA. The cause of Chiari II malformation: a unified theory. Pediatr Neurosci. 1989; 15(1): 1-12, doi: 10.1159/000120432, indexed in Pubmed: 2699756.

4. Heffez DS, Aryanpur J, Hutchins GM, et al. The paralysis associated with myelomeningocele. Neurosurg. 1990: 987-992, doi: 10.1097/00006123199006000-00011.

5. Houtrow AJ, Thom EA, Fletcher JM, et al. MOMS Investigators. A randomized trial of prenatal versus postnatal repair of myelomeningocele. N Engl J Med. 2011; 364(11): 993-1004, doi: 10.1056/NEJMoa1014379, indexed in Pubmed: 21306277.

6. Keller BA, Farmer DL. Fetal surgery for myelomeningocele: history, research, clinical trials, and future directions. Minerva Pediatr. 2015; 67(4): 341-356, indexed in Pubmed: 25698128.

7. Tulipan N, Wellons JC, Thom EA, et al. MOMS Investigators. Prenatal surgery for myelomeningocele and the need for cerebrospinal fluid shunt placement. J Neurosurg Pediatr. 2015; 16(6): 613-620, doi: 10.3171/2015.7.PEDS15336, indexed in Pubmed: 26369371.

8. Lam S, Harris D, Rocque BG, et al. Pediatric endoscopic third ventriculostomy: a population-based study. J Neurosurg Pediatr. 2014; 14(5): 455464, doi: 10.3171/2014.8.PEDS13680, indexed in Pubmed: 25238625.

9. Maher CO, Goumnerova L, Madsen JR, et al. Outcome following multiple repeated spinal cord untethering operations. J Neurosurg. 2007; 106(6 Suppl): 434-438, doi: 10.3171/ped.2007.106.6.434, indexed in Pubmed: 17566398

10. Meuli M, Meuli-Simmen C, Hutchins GM, et al. In utero surgery rescues neurological function at birth in sheep with spina bifida. Nat Med. 1995; 1(4): 342-347, doi: 10.1038/nm0495-342, indexed in Pubmed: 7585064.

11. Meuli M, Moehrlen U. Fetal surgery for myelomeningocele is effective: a critical look at the whys. Pediatr Surg Int. 2014; 30(7): 689-697, doi: 10.1007/s00383-014-3524-8, indexed in Pubmed: 24908159.

12. Zamłyński J, Olejek A, Koszutski T, et al. Comparison of prenatal and postnatal treatments of spina bifida in Poland--a non-randomized, single-center study. J Matern Fetal Neonatal Med. 2014; 27(14): 1409-1417, doi: 10.3109/14767058.2013.858689, indexed in Pubmed: 24156622.

13. Zamłyńiski J, Olejek A, Bohosiewicz J, et al. [Perinatal results of intrauterine open fetal surgery of fetuses diagnosed with myelomeningocoele-the clinical report of ten cases]. Ginekol Pol. 2007; 78(8): 647-651, indexed in Pubmed: 18050616.

14. Moron AF, Barbosa MM, Milani HJ, et al. Perinatal outcomes after open fetal surgery for myelomeningocele repair: a retrospective cohort study. BJOG. 2018; 125(10):1280-1286, doi: 10.1111/1471-0528.15312, indexed in Pubmed: 29878531

15. Adzick NS. Prospects for fetal surgery. Early Hum Dev. 2013; 89(11): 881-886, doi: 10.1016/j.earlhumdev.2013.09.010, indexed in Pubmed: 24094456.

16. Sutton LN, Adzick NS, Bilaniuk LT, et al. Improvement in hindbrain herniation demonstrated by serial fetal magnetic resonance imaging following 
fetal surgery for myelomeningocele. JAMA. 1999; 282(19): 1826-1831, doi: 10.1001/jama.282.19.1826, indexed in Pubmed: 10573273.

17. Levine D, Barnes PD, Madsen JR, et al. Central nervous system abnormalities assessed with prenatal magnetic resonance imaging. Obstet Gynecol. 1999; 94(6): 1011-1019, doi: 10.1016/s0029-7844(99)00455-x, indexed in Pubmed: 10576192.

18. Morris JE, Rickard S, Paley MNJ, et al. The value of in-utero magnetic resonance imaging in ultrasound diagnosed foetal isolated cerebral ventriculomegaly. Clin Radiol. 2007; 62(2): 140-144, doi: 10.1016/j. crad.2006.06.016, indexed in Pubmed: 17207696.

19. Zamłyński J, Horzelska E, Zamłyński M, et al. Current views on fetal surgical treatment of myelomeningocele - the Management of Myelomeningocele Study (MOMS) trial and Polish clinical experience. Ginekol Pol. 2017; 88(1):31-35, doi: 10.5603/GP.a2017.0006, indexed in Pubmed: 28157255.

20. Danzer $E$, Gerdes $M$, Bebbington MW, et al. Fetal myelomeningocele surgery: preschool functional status using the Functional Independence Measure for children (WeeFIM). Childs Nerv Syst. 2011; 27(7): 1083-1088, doi: 10.1007/s00381-011-1388-y, indexed in Pubmed: 21327591.

21. Danzer E, Thomas NH, Thomas A, et al. Long-term neurofunctional outcome, executive functioning, and behavioral adaptive skills following fetal myelomeningocele surgery. Am J Obstet Gynecol. 2016; 214(2): 269. e1-269.e8, doi: 10.1016/j.ajog.2015.09.094, indexed in Pubmed: 26440692.

22. Golombeck K, Ball RH, Lee H, et al. Maternal morbidity after maternal-fetal surgery. Am J Obstet Gynecol. 2006; 194(3): 834-839, doi: 10.1016/j. ajog.2005.10.807, indexed in Pubmed: 16522421.

23. Bennett KA, Carroll MA, Shannon CN, et al. Reducing perinatal complications and preterm delivery for patients undergoing in utero closure of fetal myelomeningocele: further modifications to the multidisciplinary surgical technique. J Neurosurg Pediatr. 2014; 14(1): 108-114, doi: 10.3171/2014.3.PEDS13266, indexed in Pubmed: 24784979.

24. Moldenhauer JS, Soni S, Rintoul NE, et al. Fetal myelomeningocele repair: the post-MOMS experience at the Children's Hospital of Philadelphia. Fetal Diagn Ther. 2015; 37(3): 235-240, doi: 10.1159/000365353, indexed in Pubmed: 25138132.

25. Al-Refai A, Ryan G, Van Mieghem T. Maternal risks of fetal therapy. Curr Opin Obstet Gynecol. 2017; 29(2): 80-84, doi: 10.1097/GCO.0000000000000346, indexed in Pubmed: 28151754.
26. Ochsenbein-Kölble N, Krähenmann F, Hüsler M, et al. Tocolysis for in utero Surgery: Atosiban Performs Distinctly Better than Magnesium Sulfate. Fetal Diagn Ther. 2017; 44(1): 59-64, doi: 10.1159/000478261.

27. Soni S, Moldenhauer JS, Spinner SS, et al. Chorioamniotic membrane separation and preterm premature rupture of membranes complicating in utero myelomeningocele repair. Am J Obstet Gynecol. 2016; 214(5): 647.e1-647.e7, doi: 10.1016/j.ajog.2015.12.003, indexed in Pubmed: 26692177.

28. da Silva SA, de Almeida MF, Moron AF, et al. Resuscitation at birth in neonates with meningomyelocele. J Perinat Med. 2014; 42(1): 113-119, doi: 10.1515/jpm-2013-0021, indexed in Pubmed: 23985428.

29. Copp AJ, Adzick NS, Chitty LS, et al. Spina bifida. Nat Rev Dis Primers. 2015; 1: 15007, doi: 10.1038/nrdp.2015.7, indexed in Pubmed: 27189655.

30. Danzer E, Johnson MP, Bebbington M, et al. Fetal head biometry assessed by fetal magnetic resonance imaging following in utero myelomeningocele repair. Fetal Diagn Ther. 2007; 22(1): 1-6, doi: 10.1159/000095833, indexed in Pubmed: 17003546.

31. American College of Obstetricians and Gynecologists. ACOG Committee opinion no. 550: maternal-fetal surgery for myelomeningocele. Obstet Gynecol. 2013; 121(1): 218-219, doi: 10.1097/01. aog.0000425666.02754.46, indexed in Pubmed: 23262964.

32. Wilson $\mathrm{R}$, Wilson $\mathrm{R}$, Audibert $\mathrm{F}$, et al. Prenatal Screening, Diagnosis, and Pregnancy Management of Fetal Neural Tube Defects. J Obstet Gynaecol Can. 2014; 36(10): 927-939, doi: 10.1016/s1701-2163(15)30444-8.

33. Meuli M, Moehrlen U, Flake A, et al. Fetal surgery in Zurich: key features of our first open in utero repair of myelomeningocele. Eur J Pediatr Surg. 2013; 23(6): 494-498, doi: 10.1055/s-0032-1329700, indexed in Pubmed: 23165510.

34. Ovaere C, Eggink A, Richter J, et al. Prenatal diagnosis and patient preferences in patients with neural tube defects around the advent of fetal surgery in Belgium and Holland. Fetal Diagn Ther. 2015; 37(3): 226-234, doi: 10.1159/000365214, indexed in Pubmed: 25301576.

35. Shanmuganathan M, Sival D, Eastwood KA, et al. Prenatal surgery for spina bifida: a therapeutic dilemma. Proceedings of the SHINE conference, Belfast. Ir J Med Sci. 2017; 187(3): 713-718, doi: 10.1007/s11845017-1709-6. 